UDC 691.32

Author: STROKOVA Valeria Valerievna, Professor, Dr. of Technical Sciences Director of Innovation scientific and educational and experimental-industrial center of «Nanostructured composite materials», Federal State-Funded Educational Institution of Higher Education «Belgorod State Technological University named after V.G. Shoukhov»; Kostukova street, 46, Belgorod, Russia, 308012; vvstrokova@gmail.com;

Author: OGURTSOVA Yulia Nikolaevna, PhD in Technical Sciences, junior research assistant of Research Institute of «Nanosystems in building material science», Federal State-Funded Educational Institution of Higher Education «Belgorod State Technological University named after V.G. Shoukhov»; Kostukova street, 46, Belgorod, Russia, 308012; ogurtsova.y@yandex.ru;

Author: BOTSMAN Larisa Nikolaevna, Associate professor, PhD in Technical Sciences, Assistant professor of the Department of Materials Science and Technology, Federal State-Funded Educational Institution of Higher Education «Belgorod State Technological University named after V.G. Shoukhov»; Kostukova street, 46, Belgorod, Russia, 308012; lora80@list.ru

\title{
EPICRYSTAL MODIFICATION OF CONSTRUCTION COMPOSITES OF DIFFERENT PURPOSE WITH APPLICATION OF GRANULATED NANOSTRUCTURED AGGREGATE
}

\section{ExTENDED Abstract:}

The paper shows that the volume impregnation of the concrete matrix in case of using granular nanostructured aggregate is an example of several anthropogenic metasomatosis such as phase replacement with the change of the chemical composition, as well as formation of new paragenesises, transformation of characteristics of final material. It is shown the impregnation of concrete with modifying solution results in microstructure impaction and homogenization; grain surface is covered with micro- and nano-sized new formations with different morphology. Considering the relevance of researches related to the development of new lightweight concrete aggregates and modification of traditionally used aggregates application of nanostructured granular aggregate for the implementation epicrystal modification of lightweight concrete based on inorganic binders is proposed. It allows creating composite macroporous structure with joint modification of the matrix on nano- and microlevel. Also, in view of increase in number of researches devoted to alkali-activated silicate and aluminosilicate systems for application as individually and as modifiers for increasing of hydrophobic properties of building materials, the possibility of creating a fine-grained concrete 
with low water absorption by the introduction of hydrophobic additives into the composition of granular nanostructured aggregate is demonstrated. During the steam treatment the fluids from solutions of sodium polysilicates and hydrophobic additives are form at the core of the granular aggregate with its later migration through the shell of the granules and spreading in the volume of the concrete matrix. Improving of performance characteristics presented construction composites for various purposes is defined by the infiltrational metasomatic transformation of crystalline matrix with the activated functional systems, obtained during the thermal activation of granulated nanostructured aggregate.

Key words: anthropogenic metasomatosis, epicrystal modification, granular nanostructured aggregate, lightweight concrete, fine-grained concrete.

DOI: dx.doi.org/10.15828/2075-8545-2016-8-5-42-59

\footnotetext{
MACHine-REAdAble information on CC-Licenses (HTML-CODE) IN METAdATA OF THE PAPER

$<$ a rel="license" href="http://creativecommons.org/licenses/by/4.0/" $><$ img alt="Creative Commons License" style="borderwidth:0" src="https://i.creativecommons.org/l/by/4.0/88x31.png" $/></ \mathrm{a}><$ br $/><$ span xmlns:dct="http://purl.org/ $\mathrm{dc} /$ terms/" href="http://purl.org/dc/dcmitype/Text" property="dct:title" rel="dct:type" $>$ Epicrystal modification of construction composites of different purpose with application of granulated nanostructured aggregate $</$ span $>$ by $<$ a xmlns:cc="http://creativecommons.org/ns\#" href="Nanotehnologii v stroitel'stve = Nanotechnologies in Construction. 2016, Vol. 8, no.5, pp. 42-59. DOI: dx.doi.org/10.15828/2075-8545-2016-8-5-42-59" property="cc:attributionName" rel=" cc:attributionURL" $>$ Strokova V.V., Ogurtsova Y.N., Botsman L.N. $</ a>$ is licensed under a $<$ a rel="license" href="http:// creativecommons.org/licenses/by/4.0/" $>$ Creative Commons Attribution 4.0 International License $</ \mathrm{a}>$. $<$ br $/>$ Based on a work at <a xmlns:det="http://purl.org/dc/terms/" href=" http://nanobuild.ru/en_EN/nanobuild-5-2016/" rel="dct:source" $>$ http://nanobuild.ru/en_EN/nanobuild-5-2016/</a $>$. $<$ br $/>$ Permissions beyond the scope of this license may be available at $<$ a xmlns:cc="http://creativecommons.org/ns\#" href="ogurtsova.y@yandex.ru" rel="cc:morePermissions">ogurtsova.y@ yandex.ru $</ a>$.
}

\section{References:}

1. Haq E.U., Padmanabhan S.K., Karim M.R.A., Licciulli A. Setting and curing of mortars obtained by alkali activation and inorganic polymerization from sodium silicate and silica aggregate. Construction and Building Materials. 2016, Vol. 105, pp. 291-296. DOI: dx.doi.org/10.1016/j.conbuildmat.2015.12.064

2. Abramovskaya I.R., Ayzenstadt A.M., Frolova M.A., Veshnyakova L.A., Tutygin A.S. Jenergetika vysokodispersnyh kompozitov gornyh porod [The energy of highly dispersed rock composites]. Nanotehnologii v stroitel'stve $=$ Nanotechnologies in Construction. 2013, Vol. 5, № 3, pp. 56-65. Available online: http://nanobuild. $\mathrm{ru} / \mathrm{ru}$ RU (Accessed date: 11.07.2016). (In Russian). 
3. Nelubova V.V., Kobzev V.A., Sivalneva M.N., Podgorniy I.I., Palshina Yu.V. Osobennosti nanostrukturirovannogo vjazhushhego v zavisimosti ot genezisa syr'ja [Features of nanostructured binder according to the genesis of raw materials]. Vestnik Belgorodskogo gosudarstvennogo tehnologicheskogo universiteta im. V.G. Shuhova [Bulletin of the Belgorod State Technological University named after V.G. Shoukhov]. 2015, № 2, pp. 25-29. (In Russian).

4. Nelubova V.V., Bukhalo A.B., Anishchenko T.A., Krivetcki V.V. Nekotorye aspekty primenenija nanorazmernyh modifikatorov s uchetom ih svojstv [Some nanosized modifiers application aspects taking into account their properties]. Vestnik Belgorodskogo gosudarstvennogo tehnologicheskogo universiteta im. V.G. Shuhova [Bulletin of the Belgorod State Technological University named after V.G. Shoukhov]. 2009, № 4, pp. 47-50. (In Russian).

5. Korzhinsky D.S. Teorija metasomaticheskoj zonal'nosti [Theory of Metasomatic Zoning]. Moscow, Nauka Publ., 1969. 115 p. (In Russian).

6. Tyutyunova F.I. Gidrogeohimija tehnogeneza [Hydrochemistry of Technogenesis]. Moscow: Nauka Publ., 1987. 335 p. (In Russian).

7. Lesovik V.S., Volodchenko A.A. Tehnogennyj metasomatoz v stroitel'nom materialovedenii [Technogenic metasomatism in construction materials]. Strojsib - 2015 . Stroitel'nye materialy - 4S: sostav, struktura, sostojanie, svojstva. Mezhdunarodnyj sbornik nauchnyh trudov [Stroysib - 2015 Building Materials - 4C: composition, structure, state, properties. International collection of research papers]. Novosibirsk, 2015, pp. 26-30. (In Russian).

8. Lesovik V.S., Volodchenko A.A. K probleme tehnogennogo metasomatoza v stroitel'nom materialovedenii [The problem of technogenic metasomatose in materials science]. Vestnik Belgorodskogo gosudarstvennogo tehnologicheskogo universiteta im. V.G. Shuhova [Bulletin of the Belgorod State Technological University named after V.G. Shoukhov]. 2015, № 4, pp. 38-41. (In Russian).

9. Strokova V.V., Maksakov A.V., Zhernovsky I.V., Ogurtsova Y.N. Granulirovannyj nanostrukturirujushhij zapolnitel' prolongirovannogo dejstvija na osnove syr'ja razlichnyh tipov dlja legkih betonov [Granular nanostructured aggregate sustained action on the basis of different types of raw materials for lightweight concrete]. Belgorod, Publishing house of BSTU named after V.G. Shoukhov, 2012. 118 p. (In Russian).

10. Strokova V.V., Zhernovsky I.V., Maksakov A.V., Ogurtsova Y.N., Solovyova L.N. Posledovatel'nost' processov formirovanija cemento-peschanoj matricy betona pri ispol'zovanii granulirovannogo nanostrukturirujushhego zapolnitelja [Consequence of forming processes cement-sand matrix of concrete with using of granu- 
lar nanostructured aggregate]. Sovremennye problemy nauki i obrazovanija [Modern problems of science and education]. 2012, № 6. Available online: http://www. science-education.ru/106-7874 (Accessed date: 24.12.2012). (In Russian).

11. Lesovik V.S., Mospan A.V., Belentcov Y.A., Ryapukhin N.V. Silikatnye izdelija na granulirovannyh zapolniteljah dlja sejsmostojkogo stroitel'stva [Load-bearing structural insulating materialwith granulated filler for earthquake resistant building]. Vestnik Belgorodskogo gosudarstvennogo tehnologicheskogo universiteta im. V.G. Shuhova [Bulletin of the Belgorod State Technological University named after V.G. Shoukhov]. 2012, № 4, pp. 62-65. (In Russian).

12. Yanakhmetov M.R., Chuykin A.E., Massalimov I.A. Modificirovanie porovoj struktury cementnyh betonov propitkoj serosoderzhashhimi rastvorami [Pore structure modification of cement concretes by impregnation with sulfur-containing compounds]. Nanotehnologii v stroitel'stve $=$ Nanotechnologies in Construction. 2015, Vol. 7, № 1, pp. 63-72. DOI: dx.doi.org/10.15828/2075-8545-2015-7-1-6372. (In Russian).

13. Inozemtcev A.S., Korolev E.V. Prochnost' nanomodificirovannyh vysokoprochnyh legkih betonov [Strength of nanomodified high-strength lightweight concretes]. Nanotehnologii v stroitel'stve $=$ Nanotechnologies in Construction. 2013, Vol. 5, № 1, pp. 24-38. Available online: http://nanobuild.ru/ru_RU (Accessed date: 11.07.2016). (In Russian).

14. Bubenkov O.A., Ketov A.A., Ketov P.A., Ketov Y.A., Lobastov S.V. Sintez melkogranulirovannogo penostekljannogo materiala iz prirodnogo amorfnogo oksida kremnija s nanorazmernoj poristost'ju [Synthesis of fine foamed glass material made from natural amorphous silica oxide with nanodimensional porosity]. Nanotehnologii v stroitel'stve = Nanotechnologies in Construction. 2010, Vol. 2, № 4, pp. 1421. Available online: http://nanobuild.ru/ru_RU (Accessed date: 29.06.2016). (In Russian).

15. Mueller A., SchnellA., Ruebner $K$. The manufacture of lightweight aggregates from recycled masonry rubble. Construction and Building Materials. 2015, Vol. 98, pp. 376-387. DOI: dx.doi.org/10.1016/j.conbuildmat.2015.07.027

16. Kanellopoulos A., Qureshi T.S., Al-Tabbaa A. Glass encapsulated minerals for selfhealing in cement based composites. Construction and Building Materials. 2015, Vol. 98, pp. 780-791. DOI: dx.doi.org/10.1016/j.conbuildmat.2015.08.127.

17. Ishchenko K.M., Suleymanova L.A., Zhernovskiy I.V. O vozmozhnosti i sposobah primenenija anionnoaktivnyh kremnijorganicheskih gidrofobizatorov dlja obrabotki materialov na osnove vspuchennogo perlitovogo peska i othodov ego proizvodstva [The possibility and methods of anionnoaktivnyh organosilicon water re- 
pellent material handling based swollen perlitic sand waste and its production]. Vestnik Belgorodskogo gosudarstvennogo tehnologicheskogo universiteta im. V.G. Shuhova [Bulletin of the Belgorod State Technological University named after V.G. Shoukhov]. 2012, № 3, pp. 60-63. (In Russian).

18. Song Z., Xue X., Li Y., Yang J., He Z., Shen S., Jiang L., Zhang W., Xu L., Zhang H., Qu J., Ji W., Zhang T., Huo L., Wang B., Lin X., Zhang N. Experimental exploration of the waterproofing mechanism of inorganic sodium silicate-based concrete sealers // Construction and Building Materials. 2016, Vol. 104, pp. 276-283. DOI: dx.doi.org/10.1016/j.conbuildmat.2015.12.069

19. Batrakov V.G. Modificirovannye betony. Teorija i praktika [Modified concrete. Theory and practice]. Moscow: Technoprojekt Publ., 1998. 768 p. (In Russian).

20. Demyanova V.S., Kalashnikov V.I., Ilyina I.E., Kazina G.N. Sistemnyj podhod pri razrabotke mnogokomponentnyh bystrotverdejushhih vysokoprochnyh betonov povyshennoj vodostojkosti [A systematic approach in the development of multicomponent quick-hardening high-strength concrete increased water resistance]. Izvestija vysshih uchebnyh zavedenij. Stroitel'stvo [Proceedings of the higher educational institutions. Building]. 2005, № 10, pp. 28-34. (In Russian).

21. Khigerovich M.I., Bayer V.E. Gidrofobno-plastificirujushhie dobavki dlja cementa, rastvorov i betonov [Hydrophobic plasticizing additives for cement, mortar and concretes]. Moscow, Stroyizdat Publ., 1979. 124 p. (In Russian).

22. Taylor H. Himija cementa [Cement Chemistry]. Moscow, Mir Publ., 1996. 560 p. (In Russian).

23. Akhverdov I.N. Osnovy fiziki betona [Basics of physics concrete]. Moscow, Stroyizdat Publ., 1981. 465 p. (In Russian).

24. Jennings H.M., Pratt P.L. On the Hydration of Portland Cement. Proceedings of the British Ceramic Society. 1979, № 28, pp. 179-193.

\section{DEAR COLLEAGUES!}

THE REFERENCE TO THIS PAPER HAS THE FOLLOWING CITATION FORMAT:

Strokova V.V., Ogurtsova Y.N., Botsman L.N. Epicrystal modification of construction composites of different purpose with application of granulated nanostructured aggregate. Nanotehnologii v stroitel'stve $=$ Nanotechnologies in Construction. 2016, Vol. 8, no.5, pp. 42-59. DOI: dx.doi.org/10.15828/2075-8545-2016-8-542-59. (In Russian). 
удК 691.32

Автор: СТРОКОВА Валерия Валерьевна, профессор, д-р техн. наук, директор ИНО и ОПЦ «Наноструктурированных композиционных материалов», ФГБОУ ВО «Белгородский государственный технологический университет им. В.Г. Шухова»; ул. Костюкова, 46, Белгород, Россия, 308012; vvstrokova@gmail.com;

Автор: ОГУРЦОВА Юлия Николаевна, канд. техн. наук, мл. научный сотрудник НИИ «Наносистемы в строительном материаловедении», ФГБОУ ВО «Белгородский государственный технологический университет им. В.Г. Шухова»; ул. Костюкова, 46, Белгород, Россия, 308012; ogurtsova.y@yandex.ru;

Автор: БОЦМАН Лариса Николаевна, доцент, канд. техн. наук, доцент кафедры материаловедения и технологии материалов, ФГБОУ ВО «Белгородский государственный технологический университет им. В.Г. Шухова»; ул. Костюкова, 46, Белгород, Россия, 308012; lora80@list.ru

\section{ЭПИКРИСТАЛЛИЗАЦИОННОЕ МОДИФИЦИРОВАНИЕ СТРОИТЕЛЬНЫХ КОМПОЗИТОВ РАЗЛИЧНОГО ФУНКЦИОНАЛЬНОГО НАЗНАЧЕНИЯ С ИСПОЛЬЗОВАНИЕМ ГРАНУЛИРОВАННОГО НАНОСТРУКТУРИРУЮЩЕГО ЗАПОЛНИТЕЛЯ}

АННОТАЦИЯ К СТАТЬЕ (АВТОРСКОЕ РЕЗЮМЕ, РЕФЕРАТ):

В работе показано, что объемная пропитка бетонной матрицы при использовании гранулированного наноструктурирующего заполнителя выступает примером некоторых процессов техногенного метасоматоза - процесса замещения фаз с изменением химического состава, формирования новых парагенезисов, преобразования свойств конечного материала. Показано, что в результате пропитки модифицирующим раствором микроструктура бетона становится более плотной и однородной, поверхность зерен покрыта микро- и наноразмерными новообразованиями различной морфологии. Ввиду актуальности направления, связанного с разработкой новых заполнителей легких бетонов и модификации традиционных, предлагается использование гранулированного наноструктурирующего заполнителя для реализации эпикристализационного модифицирования легких бетонов на основе неорганических вяжущих. Это позволяет создать макропористую структуру композита с одновременной модификацией матрицы на нано- и микроуровне. Также ввиду увеличения объемов исследований в области щелочеактивированных силикатных и алюмосиликат- 
ных систем для применения как в самостоятельном виде, так и в качестве модификаторов, в том числе для повышения гидрофобности строительных материалов, показана возможность создания мелкозернистого бетона с пониженным водопоглощением путем введения в состав гранулированного наноструктурирующего заполнителя гидрофобизирующей добавки. При тепловлажностной обработке в ядре гранулированного заполнителя формируются флюиды из растворов полисиликатов натрия с гидрофобизирующей добавкой, происходит их миграция через оболочку гранул и распределение в объеме бетонной матрицы. Улучшение эксплуатационных характеристик представленных строительных композитов различного функционального назначения обусловлено инфильтрационным метасоматическим преобразованием кристаллической матрицы активированными функциональными системами, полученными при термической активации гранулированного наноструктурирующего заполнителя.

Ключевые слова: техногенный метасоматоз, эпикристаллизационное модифицирование, гранулированный наноструктурирующий заполнитель, легкий бетон, мелкозернистый бетон.

DOI: dx.doi.org/10.15828/2075-8545-2016-8-5-42-59

МАШИНОЧИТАЕМАЯ ИНФОРМАЦИЯ О СС-ЛИЦЕНЗИИ В МЕТАДАННЫХ СТАТЬИ (HTML-КОД):

$<$ a rel="license" href="http://creativecommons.org/licenses/by/4.0/"><img alt="Лицензия Creative Commons" style="border-width:0" src="https://i.creativecommons.org/l/by/4.0/88x31.png" / $></$ a $><$ br $/>$ Произведение «<span xmlns:dct="http://purl.org/dc/terms/" href="http://purl.org/dc/dcmitype/Text" property="dct:title" rel="dct:type">Эпи кристаллизационное модифицирование строительных композитов различного функционального назначения с использованием гранулированного наноструктурирующего заполнителя</span>» созданное автором по имени <a xmlns:cc="http:// creativecommons.org/ns\#" href="Нанотехнологии в строительстве. - 2016. - Tом 8, № 5. - C. 42-59. - DOI:dx.doi. org/10.15828/2075-8545-2016-8-5-42-59" property="сc:attributionName" rel="cc:attributionURL">Cтрокова В.В., Огурцова Ю.Н., Боцман Л.Н. </a>, публикуется на условиях <a rel="license" href="http://creativecommons.org/licenses/ by/4.0/">лицензии Creative Commons «Attribution» ("Атрибуция») 4.0 Всемирная $</ \mathrm{a}>$. $<$ br $/>$ Основано на произведении с <a xmlns:dct="http://purl.org/dc/terms/" href="http://nanobuild.ru/ru_RU/nanobuild-5-2016/" rel="dct:source">http:// nanobuild.ru/ru_RU/nanobuild-5-2016/</a $>$. $<$ br / > Разрешения, выходящие за рамки данной лицензии, могут быть доступны на странице <a xmlns:cc="http://creativecommons.org/ns\#" href="ogurtsova.y@yandex.ru" rel="cc:morePermission s">ogurtsova.y@yandex.ru</a $>$.

учетом актуальности направления, связанного с адаптацией природных процессов при синтезе и производстве современных композиционных материалов и их составляющих, перспективным является использование механизмов геологических процессов и энергетики сырьевых материалов при модифицировании кристаллической матрицы строительных композитов [1-4]. 
В частности, при производстве цементных материалов может быть использован изученный и описанный в геологической литературе процесс инфильтрационного метасоматоза [5]. Метасоматоз (от греч «мета» - после, «сома» - тело) - эндогенный процесс твердофазового замещения пород под действием флюида, приводящий к существенному изменению их минерального и химического состава [5]. При переносе природных процессов на техногенные рядом исследователей описаны примеры техногенного метасоматоза. Техногенный метасоматоз трактуется различным образом: как необратимый химический процесс локального замещения минералов горных пород новыми твердыми фазами в результате их взаимодействия с метаморфизованными подземными водами [6]; как стадия в эволюции строительных материалов, характеризующаяся приспособлением композита к изменяющимся, при эксплуатации зданий и сооружений, условиям, т.е. как химическое взаимодействие в системе «вяжущее - заполнитель - наполнитель - добавки - поровый - раствор - окружающая среда» с изменением химического состава, при котором растворение исходных компонентов и синтез новообразований происходит почти одновременно [7, 8].

Реализация данного механизма в цементной матрице может быть осуществлена путем создания условий для формирования активированных функциональных (протогенетических) систем при термической обработке композита. Формирование таких систем возможно при использовании гранулированного наноструктурирующего заполнителя (ГНЗ) $[9,10]$. Введение данного заполнителя в состав бетонной смеси и последующая термическая обработка обеспечивает эпикристаллизационное модифицирование [9] кристаллической матрицы материала.

Эпикристаллизационным (эпи... - от греч. ері́ - после) модифицированием при синтезе искусственных композитов (строительных материалов) на основе неорганических вяжущих называется инфильтрационное метасоматическое преобразование активированными функциональными (протогенетическими) минеральными системами кристаллической матрицы материала с целью образования новых парагенезисов или преобразования поверхностей минеральных индивидов [9].

Компонентами ГНЗ являются: кремнеземное сырье, щелочной активатор, жидкое стекло в качестве связки, портландцемент (а также известь или мел) в качестве материала оболочки. Физико-механические и функциональные характеристики ГНЗ определяются: особенностями 
кремнеземного сырья, в частности, содержанием аморфного $\mathrm{SiO}_{2}$; соотношением кремнеземного и щелочного компонентов; условиями производства (параметрами гранулятора) (табл. 1).

Таблица 1

\section{Свойства гранулированного наноструктурирующего заполнителя}

\begin{tabular}{|c|c|c|c|c|c|}
\hline \multicolumn{3}{|c|}{ Состав заполнителя } & \multicolumn{3}{|c|}{ Свойства заполнителя } \\
\hline \multicolumn{2}{|c|}{ Кремнеземное сырье } & \multirow{2}{*}{$\begin{array}{l}\text { Дозировка } \\
\text { щелочного } \\
\text { активатора, } \\
\text { \% от массы } \\
\text { кремнезем- } \\
\text { ного сырья }\end{array}$} & \multirow[b]{2}{*}{$\begin{array}{c}\text { Размер } \\
\text { гранул, мм }\end{array}$} & \multirow[b]{2}{*}{$\begin{array}{c}\text { Насыпная } \\
\text { плотность, } \\
\text { кг } / \mathbf{M}^{3}\end{array}$} & \multirow{2}{*}{\begin{tabular}{|c} 
Прочность \\
при сдавли \\
вании \\
в цилиндре \\
МПа
\end{tabular}} \\
\hline Вид & $\begin{array}{l}\text { Генетиче- } \\
\text { ский тип }\end{array}$ & & & & \\
\hline $\begin{array}{c}\text { Кислота } \\
\text { кремниевая } \\
\text { водная }\end{array}$ & $\begin{array}{l}\text { Хемогенный } \\
\text { техногенный }\end{array}$ & 30 & $0,63-10$ & $700-750$ & $0,3-0,49$ \\
\hline Опока & $\begin{array}{c}\text { Хемогенный } \\
\text { осадочный }\end{array}$ & 20 & $0,63-10$ & $720-870$ & $0,32-1,47$ \\
\hline Трепел & $\begin{array}{c}\text { Органоген- } \\
\text { ный осадоч- } \\
\text { ный }\end{array}$ & 19 & $0,63-10$ & $758-873$ & $0,85-1,47$ \\
\hline Зола-уноса & $\begin{array}{l}\text { Пирогенный } \\
\text { техногенный }\end{array}$ & 2 & $0,315-1,25$ & $851-895$ & $1,50-1,64$ \\
\hline
\end{tabular}

Принцип действия ГНЗ заключается в щелочной активации кремнеземного сырья в ядре заполнителя с последующей пропиткой бетонной матрицы образовавшимся раствором. Эпикристаллизационное модифицирование бетонной матрицы может быть использовано для получения строительных композитов различного функционального назначения [9].

\section{Легкие бетоны}

Использование ГНЗ в легких бетонах в качестве альтернативы керамзитовому гравию обусловлено их способностью к активному химическому взаимодействию с цементной матрицей, повышению ее водо- 
стойкости, прочностных характеристик и снижению теплопроводности композита в целом. Как правило, использование пористых заполнителей для легких бетонов, как природных, так и искусственных, приводит к существенному влагопоглощению, что существенно ухудшает их теплозащитные характеристики при эксплуатации. Также большинство традиционных заполнителей имеют слабую контактную зону с цементным камнем, обусловленную отсутствием либо слабым химическим взаимодействием вещества заполнителя с продуктами гидратации цемента. В данном случае контактный слой включает два независимых компонента - контактную зону заполнителя, прилегающую к цементному камню, и контактную зону цементного камня около поверхности заполнителя. Поиск путей решения данной проблемы является актуальным направлением исследований как в России, так и за рубежом [12-16].

Использование ГНЗ позволяет исключить данный недостаток традиционных заполнителей за счет воздействия образующегося в ядре ГНЗ, во время тепловлажностной обработки (ТВО), раствора полисиликатов натрия на цементно-песчаную матрицу бетона и формирования плотной контактной зоны. Анализ микроструктурных особенностей ГНЗ и бетонной матрицы после ТВО позволяет описать механизм эпикристаллизационного модифицирования.

Во время ТВО изделий из бетона на основе ГНЗ отмечается активное взаимодействие в ядре между кремнеземной породой и гидроксидом натрия с образованием водорастворимых силикатов натрия. Из ядра выщелачивается аморфный кремнезем, и в результате на месте ГНЗ остаются пустоты, наполненные малоактивными кристаллическими частицами (рис. 1).

Мигрируя через трещины защитной оболочки гранул, силикаты натрия пропитывают цементно-песчаную матрицу изделия (рис. 2). Данный процесс ведет к формированию малорастворимых соединений на основе силикатов натрия, в т.ч. пленки натросилита на поверхности порового пространства бетона (рис. 3), исправлению («залечиванию») дефектов в структуре цементно-песчаной матрицы, заполнению микрои наноразмерных пор цементного камня, что способствует формированию монолитной контактной зоны между заполнителем и бетонной матрицей, препятствует процессам миграции воды, повышая тем самым водонепроницаемость строительного изделия в целом. 

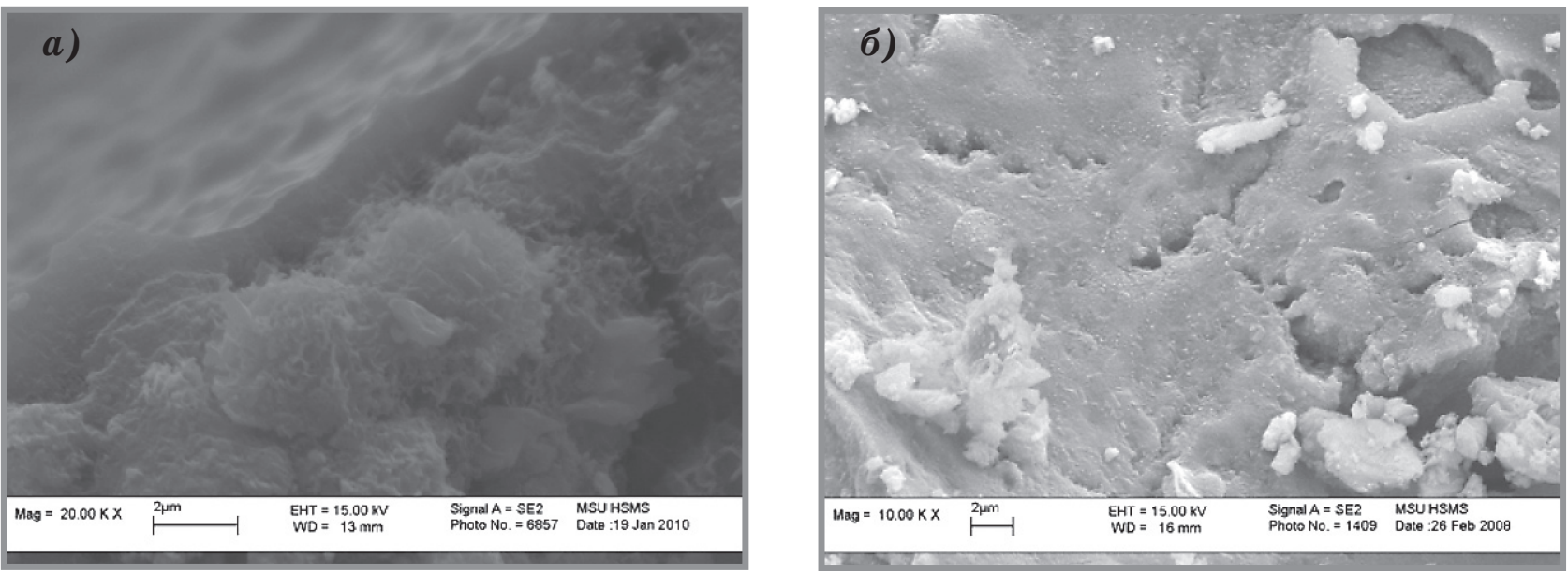

Рис. 1. Внутренняя поверхность ядра ГНЗ после ТВО:

а) на основе кислоты кремниевой водной;

б) на основе опоки (респ. Мордвия)
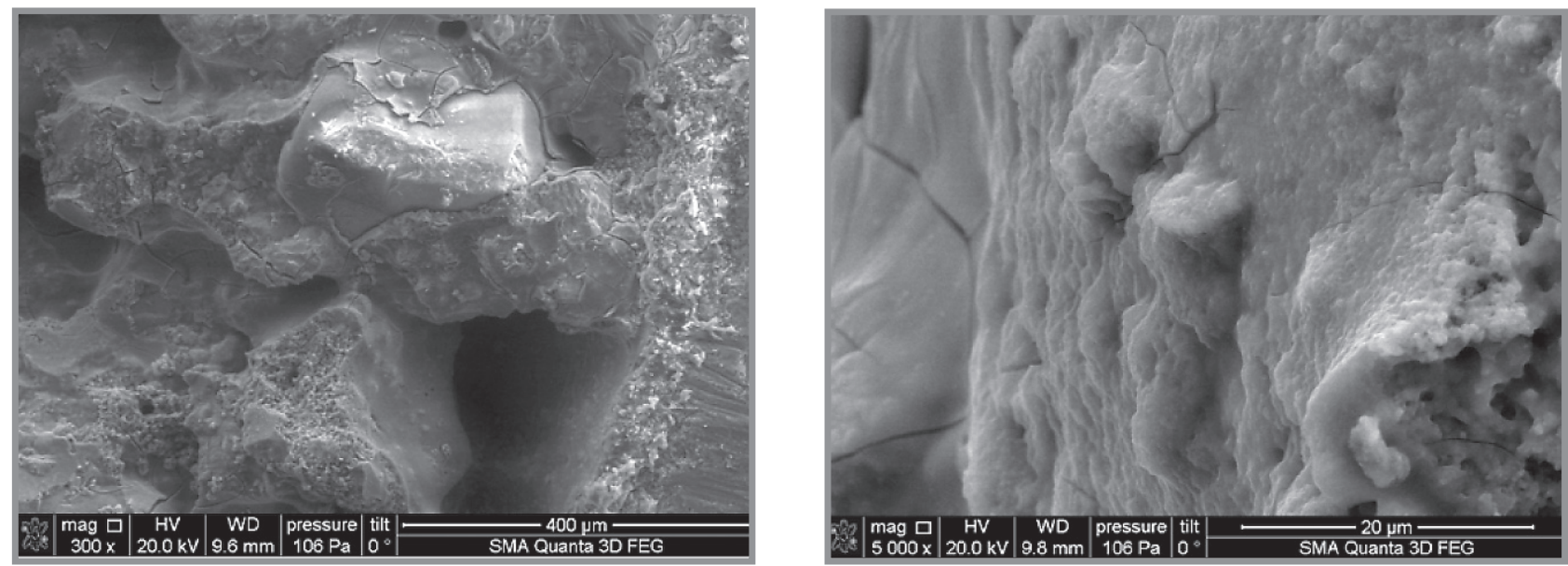

Рис. 2. Структура бетона с ГНЗ после ТВО

Введение гранулированного наноструктурирующего заполнителя пролонгированного действия в состав цементной матрицы легкого бетона позволяет при помощи эпикристаллизационного модифицирования системы создавать плотную, монолитную композицию с минимальным количеством дефектов и трещин, что повышает прочностные показатели бетона, а также снижает водопоглощение, позволяет сохранять низкие показатели теплопроводности во влажных условиях (табл. 2). 


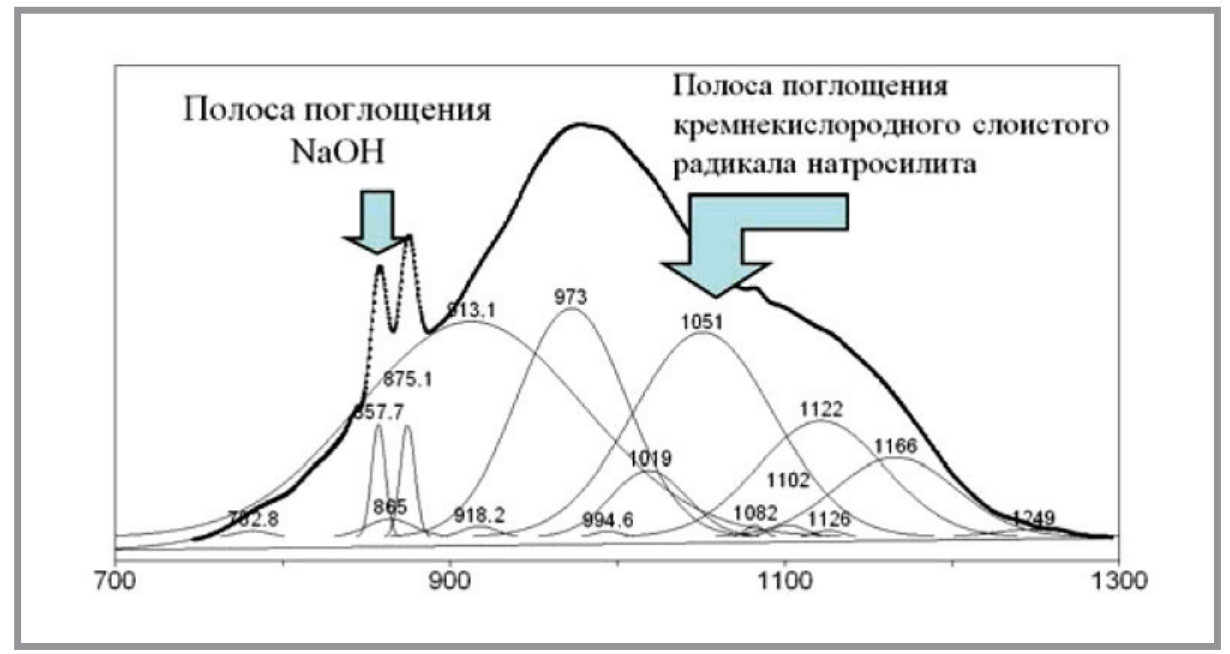

Рис. 3. ИК-спектральная диагностика 2D-нанообразований в цементном камне с ГНЗ [10]

Таблица 2

\section{Свойства легкого бетона с гранулированным наноструктурирующим заполнителем}

\begin{tabular}{|c|c|c|c|c|}
\hline \multirow[b]{2}{*}{$\begin{array}{c}\text { Вид } \\
\text { заполнителя }\end{array}$} & \multicolumn{4}{|c|}{ Свойства легкого бетона } \\
\hline & $\begin{array}{c}\text { Средняя } \\
\text { плотность, } \\
\text { кг } / \mathbf{M}^{3}\end{array}$ & $\begin{array}{c}\text { Предел } \\
\text { прочности при } \\
\text { сжатии, МПа }\end{array}$ & $\begin{array}{c}\text { Водопогло- } \\
\text { щение, \% }\end{array}$ & $\begin{array}{c}\text { Теплопрово- } \\
\text { дность, } \\
\text { Вт/(м·К) }\end{array}$ \\
\hline $\begin{array}{l}\text { ГНЗ на основе: } \\
\text { - кислоты кремниевой } \\
\text { водной }\end{array}$ & $1200-1300$ & $10,5-11,2$ & $4-6$ & $0,15-0,30$ \\
\hline - опоки & $1700-1740$ & $7,3-11,8$ & $7-10$ & $0,37-0,38$ \\
\hline - трепела & $1650-1720$ & $7,0-11,3$ & $7-10$ & $0,31-0,32$ \\
\hline Керамзитовый гравий & $1200-1300$ & $11,5-13,5$ & $15-20$ & $0,36-0,47$ \\
\hline
\end{tabular}

\section{Мелкозернистые бетоны с пониженным водопоглощением}

Традиционно для повышения гидрофобности бетонных изделий используются гидрофобизирующие покрытия или гидрофобизирующие добавки $[17,18]$. Согласно принципу действия, гидрофобизирующие 
добавки способны «точечно» или в виде полимерных нерастворимых пленок адсорбироваться на поверхности минеральных компонентов, в частности, цементных частиц. После введения гидрофобизирующей добавки с сухими компонентами бетонной смеси или с водой затворения на поверхности минеральных частиц образуется «ворс» из углеводородных радикалов, который сокращает диффузию воды к их поверхности и уменьшает смачивание. В результате скорость гидратации цемента снижается, что негативно сказывается на прочности конечных изделий [19-21].

Использование ГНЗ в качестве носителя гидрофобизирующей добавки позволяет исключить процесс формирования гидрофобных адсорбционных оболочек на поверхности цементных частиц. В данной работе предлагается механизм взаимодействия компонентов в системе «мелкозернистый бетон - гранулированный заполнитель» при ТВО (рис. 4), основанный на двух параллельных процессах.

Первый процесс связан с действием гидрофобизирующей добавки, инкапсулированной в гранулированный заполнитель.

Предварительная выдержка (рис. 4 а). Ранее установлено оптимальное и достаточное время предварительной выдержки бетона с ГНЗ до ТВО - 10 часов [9]. $К$ этому моменту $[19,22]$ уже активно идут процессы гидратации клинкерных минералов с образованием $\mathrm{C}-\mathrm{S}-\mathrm{H}$ и $\mathrm{CH}$. Частицы цемента покрываются слоем новообразований - «гелевой оболочкой», продолжается постепенное поглощение воды из пор геля и гидратных (сольватных) оболочек [23], образованных вокруг поверхности

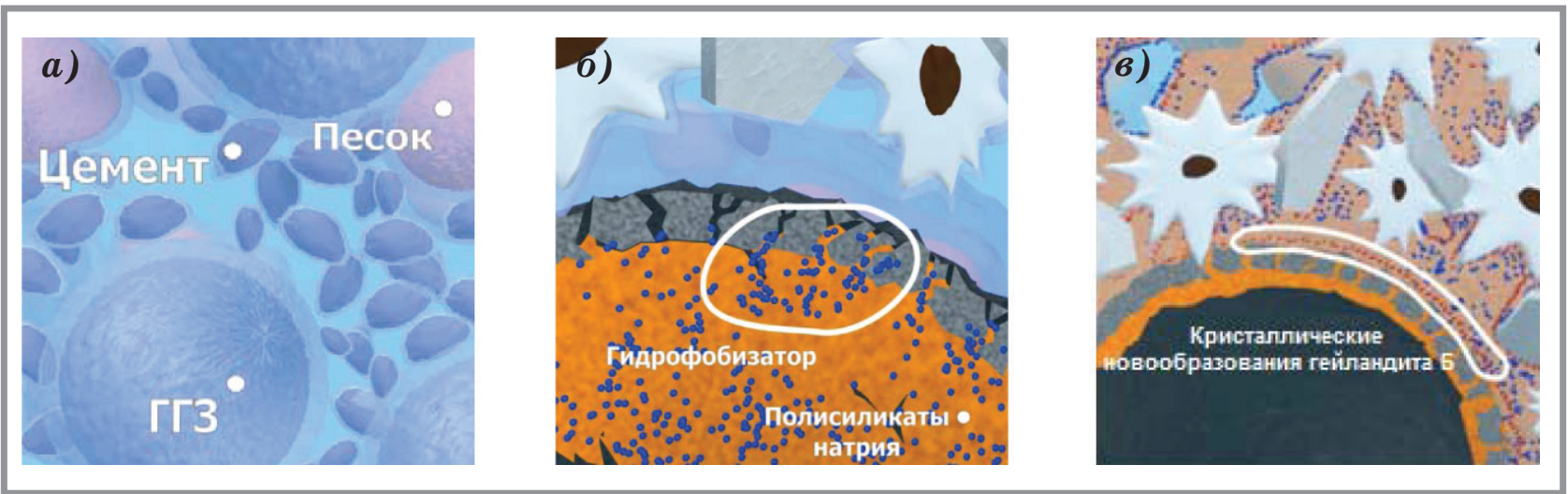

Рuc. 4. Механизм взаимодействия компонентов в системе «кристаллическая матрица - гранулированный заполнитель» 
цементных зерен, и уплотнение геля. $К$ этому времени в системе имеется значительное количество портландита (он начинает кристаллизоваться уже после 4 часов гидратации) [24].

При использовании гранулированного заполнителя в результате предварительного твердения в течение 10 ч частично прогидратированные зерна цемента покрываются слоем новообразований - «гелевой оболочкой», что предотвращает образование «ворса» из углеводородных радикалов гидрофобизатора.

При ТВО в ядре гранулированного заполнителя (рис. 4 б) формируются флюиды из растворов полисиликатов натрия с гидрофобизирующей добавкой, происходит их миграция через оболочку гранул и распределение в объеме бетонной матрицы. Это обеспечивает: гидрофобизацию поверхностей межпоровых перегородок бетонной матрицы; заполнение гидрофобизирующим раствором пор и пустот между зернами мелкого заполнителя и цемента, покрытых сольватной оболочкой, не предотвращая диффузию воды, т.е. без нарушения процессов гидратации.

Таким образом, реализуется механизм гидрофобизации бетонной матрицы «изнутри», равномерная пропитка пор и пустот гидрофобизирующим раствором по всей толще материала.

Второй процесс обусловлен взаимодействием алюмосиликатных растворов с продуктами гидратации, что приводит к формированию в составе цементного камня водонерастворимых новообразований (рис. 4 в, рис. 5). Изучая и описывая процессы, протекающие в зоне контакта ГНЗ с бетонной матрицей, нами было предложено рассматривать их как локальное (в силу малых зон воздействия флюидов) инфильтрационное метасоматическое воздействие [10]. В результате эпикристаллизационного воздействия происходит изменение как состава композита, так и его структуры на различных размерных уровнях.

При использовании ГНЗ с гидрофобизирующей добавкой реализуется механизм эпикристаллизационного воздействия коллоидных алюмосиликатных растворов, формируемых при ТВО в ядре заполнителя и мигрирующих в цементную матрицу, на структурообразование цементного камня, заключающийся в формировании каркасных алюмосиликатных минеральных образований при взаимодействии с $\mathrm{CaO}$. Гейландитовая фаза кристаллизируется на минеральных компонентах цементного камня, как на подложке. Формируемый кристаллический 


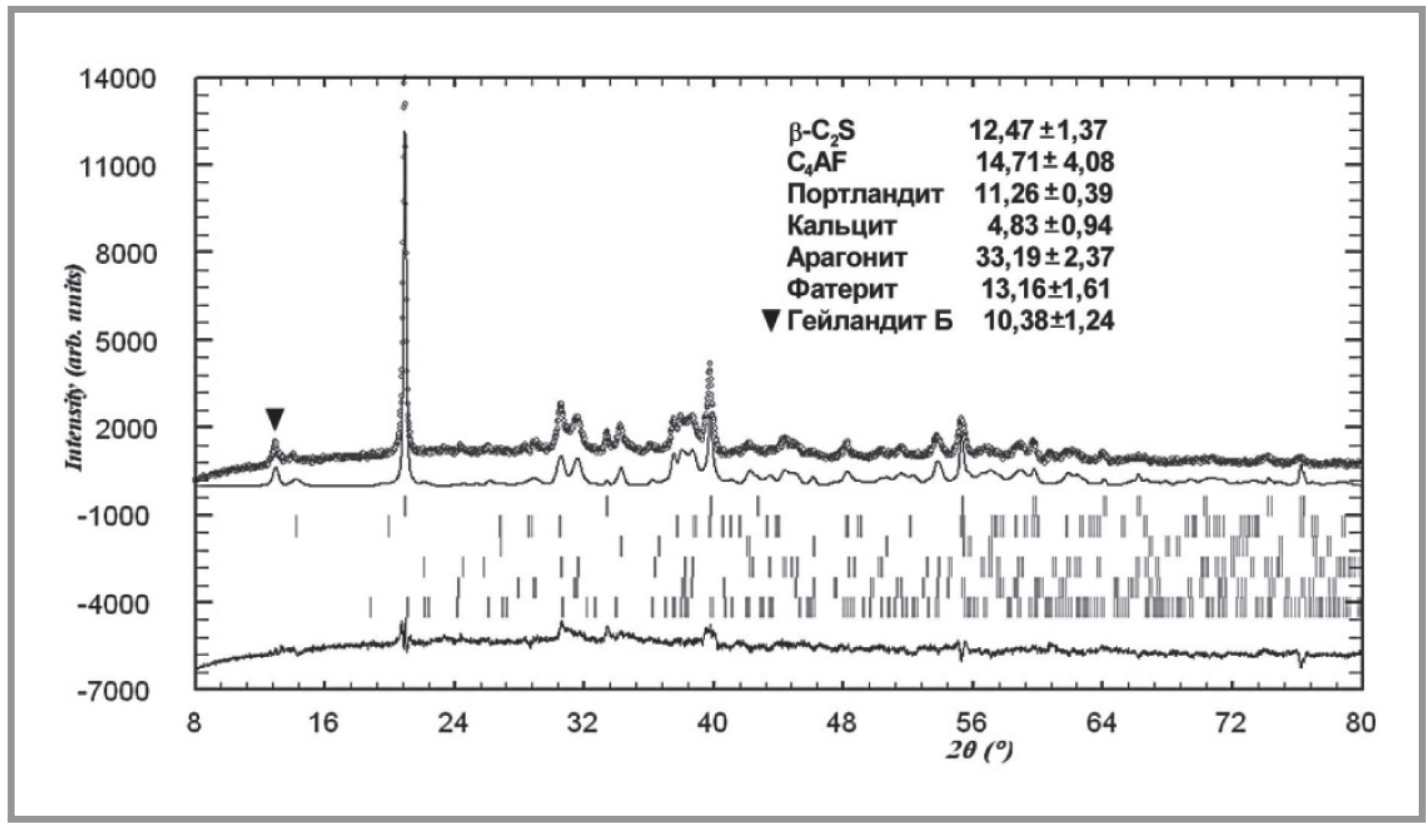

Рuc. 5. Количественный РФА (масс.\% ) портландцементного вяжущего, обработанного в растворе «зола-уноса+NaOH+ГКЖ-11»

алюмосиликатный каркас гейландита Б, представляющий собой тонкое покрытие с довольно высокой ретикулярной плотностью, инкапсулирует минеральные компоненты цементного камня, что обеспечивает пролонгированную объемную гидрофобизацию композита и подтверждается пониженными показателями водопоглощения (табл. 3).

Таблица 3

Свойства мелкозернистого бетона с гидрофобизирующим гранулированным заполнителем

\begin{tabular}{|c|c|c|c|}
\hline \multirow[b]{2}{*}{ Вид заполнителя } & \multicolumn{3}{|c|}{ Свойства МЗБ на ГНЗ } \\
\hline & $\begin{array}{c}\text { Предел } \\
\text { прочности } \\
\text { при сжатии, МПа }\end{array}$ & $\begin{array}{c}\text { Водопоглощение, } \\
\%\end{array}$ & $\begin{array}{c}\text { Марка } \\
\text { по морозостой- } \\
\text { кости }\end{array}$ \\
\hline $\begin{array}{l}\text { ГНЗ на основе } \\
\text { - опоки и стеарата } \\
\text { кальция }\end{array}$ & $28,5-46,2$ & $1,45-2,53$ & $75-200$ \\
\hline - золы-уноса и ГКЖК-11 & $26,2-45,3$ & $2,35-3,28$ & $75-200$ \\
\hline
\end{tabular}


В работе предложен механизм эпикристаллизационного воздействия коллоидных силикатных и алюмосиликатных растворов, формируемых при ТВО в ядре гранулированного наноструктурирующего заполнителя и мигрирующих в цементную матрицу, на структурообразование цементного камня, заключающийся в формировании каркасных силикатных и алюмосиликатных минеральных образований при взаимодействии с СаО. Установленная совокупность процессов, протекающих при формировании разработанных композитов, является инструментом для проектирования и управляемого синтеза легких и мелкозернистых бетонов, через направленное воздействие на их макро-, микрои наномасштабную структурную организацию. Показана возможность создания композитов с пониженным водопоглощением путем введения гидрофобизирующей добавки в состав гранулированного наноструктурирующего заполнителя.

Работа выполнена при финансовой поддержке РФФИ, проект 14-41-08024.

УВАЖАЕМЫЕ КОЛЛЕГИ!

ПРИ ИСПОЛЬЗОВАНИИ МАТЕРИАЛА ДАННОЙ СТАТЬИ

ПРОСИМ ДЕЛАТЬ БИБЛИОГРАФИЧЕСКУЮ ССЫЛКУ НА НЕЁ:

Строкова В.В., Огуриова Ю.Н., Боцлан Л.Н. Эпикристаллизационное модифицирование строительных композитов различного функционального назначения с использованием гранулированного наноструктурирующего заполнителя // Нанотехнологии в строительстве. - 2016. - Том 8, № 5. - C. 42-59. - DOI: dx.doi.org/10.15828/2075-8545-2016-8-5-42-59.

\section{DeAR COLlEAgues!}

THE REFERENCE TO THIS PAPER HAS THE FOLLOWING CITATION FORMAT:

Strokova V.V., Ogurtsova Y.N., Botsman L.N. Epicrystal modification of construction composites of different purpose with application of granulated nanostructured aggregate. Nanotehnologii v stroitel'stve = Nanotechnologies in Construction 2016, Vol. 8, no. 5, pp. 42-59. DOI: dx.doi.org/10.15828/2075-8545-2016-8-542-59. (In Russian). 


\section{Библиографический список:}

1. Haq E.U., Padmanabhan S.K., Karim M.R.A., Licciulli A. Setting and curing of mortars obtained by alkali activation and inorganic polymerization from sodium silicate and silica aggregate // Construction and Building Materials. - 2016. Vol. 105. - P. 291-296. - DOI: dx.doi.org/10.1016/j.conbuildmat.2015.12.064

2. Абраловская И.Р., Айзенштадт А.М., Фролова М.А., Вешнякова Л.А., Тутыгин A.C. Энергетика высокодисперсных композитов горных пород // Нанотехнологии в строительстве. - 2013. - Tом 5, № 3. - C. 56-65. - URL: http:// nanobuild.ru/ru_RU (дата обращения: 11.07.2016).

3. Нелюбова В.В., Кобзев В.А., Сивальнева М.Н., Подгорный И.И., Пальшина Ю.В. Особенности наноструктурированного вяжущего в зависимости от генезиса сырья // Вестник Белгородского государственного технологического университета им. В.Г. Шухова. - 2015. - № 2. - С. 25-29.

4. Нелюбова В.В., Бухало А.Б., Анищенко Т.А., Кривецкий В.В. Некоторые аспекты применения наноразмерных модификаторов с учетом их свойств / Вестник Белгородского государственного технологического университета им. В.Г. Шухова. - 2009. - № 4. - С. 47-50.

5. Коржинский Д.С. Теория метасоматической зональности. - Москва: Наука, 1969. - $115 \mathrm{c}$.

6. Тютюнова Ф.И. Гидрогеохимия техногенеза. - Москва: Наука, 1987. - 335 с.

7. Лесовик В.С. Техногенный метасоматоз в строительном материаловедении // Стройсиб - 2015. Строительные материалы - 4С: состав, структура, состояние, свойства. Международный сборник научных трудов. - Новосибирск, 2015. C. 26-30.

8. Лесовик B.C., Володченко А.A. $\mathrm{K}$ проблеме техногенного метасоматоза в строительном материаловедении // Вестник Белгородского государственного технологического университета им. В.Г. Шухова. - 2015. - № 4. - С. 38-41.

9. Строкова В.В., Максаков А.В., Жерновский И.В., Огуриова Ю.Н. Гранулированный наноструктурирующий заполнитель пролонгированного действия на основе сырья различных типов для легких бетонов // Белгород: Изд-во БГТУ им. В.Г. Шухова, 2012. - 118 с.

10. Строкова В.В., Жерновский И.В., МаксаковА.В., Огуриова Ю.Н., СоловьеваЛ.Н. Последовательность процессов формирования цементо-песчаной матрицы бетона при использовании гранулированного наноструктурирующего заполнителя // Современные проблемы науки и образования. - 2012. - № 6 . - URL: http://www.science-education.ru/106-7874 (дата обращения: 24.12.2012).

11. Лесовик В.С., Мосьпан А.В., Беленцов Ю.А., Ряпухин Н.В. Силикатные изделия на гранулированных заполнителях для сейсмостойкого строительства // Вестник Белгородского государственного технологического университета им. В.Г. Шухова. - 2012. - № 4. - С. 62-65. 
12. Янахлетов М.Р., Чуйкин А.Е., Массалилов И.А. Модифицирование поровой структуры цементных бетонов пропиткой серосодержащими растворами / / Нанотехнологии в строительстве. - 2015. - Том 7, № 1. - C. 63-72. - DOI: dx.doi. org/10.15828/2075-8545-2015-7-1-63-72

13. Инозелиев A.C., Королев E.В. Прочность наномодифицированных высокопрочных легких бетонов / Н Нанотехнологии в строительстве. - 2013. - Том 5, № 1. C. 24-38. - URL: http://nanobuild.ru/ru_RU (дата обращения: 11.07.2016).

14. Бубенков О.А., Кетов А.А., Кетов П.А., Кетов Ю.А., Лобастов С.В. Синтез мелкогранулированного пеностеклянного материала из природного аморфного оксида кремния с наноразмерной пористостью // Нанотехнологии в строительстве. - 2010. - Tом 2, № 4. - C. 14-21. - URL: http://nanobuild.ru/ru_RU (дата обращения: 29.06.2016).

15. Mueller A., Schnell A., Ruebner $K$. The manufacture of lightweight aggregates from recycled masonry rubble // Construction and Building Materials. - 2015. Vol. 98. - P. 376-387. - DOI: dx.doi.org/10.1016/j.conbuildmat.2015.07.027

16. Kanellopoulos A., Qureshi T.S., Al-Tabbaa A. Glass encapsulated minerals for selfhealing incementbased composites / / Construction and Building Materials. - 2015.Vol. 98. - P. 780-791. - DOI: dx.doi.org/10.1016/j.conbuildmat.2015.08.127

17. Ищенко К.М., Сулейланова Л.А., Жерновский И.В. О возможности и способах применения анионноактивных кремнийорганических гидрофобизаторов для обработки материалов на основе вспученного перлитового песка и отходов его производства // Вестник Белгородского государственного технологического университета им. В.Г. Шухова. - 2012. - № 3. - С. 60-63.

18. Song Z., Xue X., Li Y., Yang J., He Z., Shen S., Jiang L., Zhang W., Xu L., Zhang H., Qu J., Ji W., Zhang T., Huo L., Wang B., Lin X., Zhang $N$. Experimental exploration of the waterproofing mechanism of inorganic sodium silicate-based concrete sealers // Construction and Building Materials. - 2016. - Vol. 104. - P. 276283. - DOI: dx.doi.org/10.1016/j.conbuildmat.2015.12.069

19. Батраков В.Г. Модифицированные бетоны. Теория и практика. - М.: Технопроект, 1998. - 768 с.

20. Дельянова В.С., Калашников В.И., Ильина И.Е., Казина Г.Н. Системный подход при разработке многокомпонентных быстротвердеющих высокопрочных бетонов повышенной водостойкости // Известия высших учебных заведений. Строительство. - 2005. - № 10. - С. 28-34.

21. Хигерович М.И., Байер В.Е. Гидрофобно-пластифицирующие добавки для цемента, растворов и бетонов. - М.: Стройиздат, 1979. - 124 с.

22. Тейлор Х. Химия цемента. - М.: Мир, 1996. - 560 с.

23. Ахвердов И.Н. Основы физики бетона. - М.: Стройиздат, 1981. -465 с.

24. Jennings H.M., Pratt P.L. On the Hydration of Portland Cement // Proceedings of the British Ceramic Society. - 1979. - № 28. - P. 179-193. 